\title{
Voces y memorias del trauma: una propuesta metodológica para indagar las resistencias a la represión dictatorial en Argentina1
}

\author{
Rubén Isidoro Kotler * \\ Universidad Nacional de Tucumán
}

\section{Resumen}

El uso de la metodología de historia oral supone nuevas perspectivas y al mismo tiempo desafíos en el estudio de pasados traumáticos recientes. Las reflexiones que se propone el artículo surgen de mi propia experiencia tras haber indagado en la historia del movimiento de derechos humanos de Tucumán a partir de la recuperación de la memoria oral de sus militantes. Si bien al adentrarnos al estudio de pasados dictatoriales y a sus consecuentes transiciones, recurrimos a los métodos tradicionales de búsqueda de fuentes, la dificultad de encontrar documentos escritos que den cuenta de lo sucedido, debemos recurrir al testimonio de quienes han sido actores sociales reconocidos en dicho proceso. El usos de las fuentes orales que se construyen entonces, a partir de las entrevistas con militantes de las distintas organizaciones, supone un desafío en el que la cuestión de la temporalidad se evidencia como central, toda vez que el proceso político en cuestión, sigue abierto. Si bien se plantean una serie de desafíos a los que debe enfrentarse el investigador, las posibilidades que nos brinda la historia oral en estas perspectivas son importantes y saber cómo lidiar con ellas, puede contribuir al arribo a buen puerto en nuestra investigación. Como aseguraba Alessandro Portelli, "la historia oral no solo nos habla de lo ocurrido, sino también de lo que la gente quiso que ocurriera, lo que la gente creyó que estaba ocurriendo". La particularidad en el caso del estudio de la historia del movimiento de derechos humanos de Argentina es que es un proceso aún abierto por lo que la historia no solo es reciente, sino también presente.

\footnotetext{
${ }^{1}$ Las siguientes reflexiones surgen de la experiencia en la investigación sobre la historia del movimiento de derechos humanos de Tucumán cuyo resultado final fue mi tesis de doctorado defendida el 4 de julio de 2013 en la Universidad de Salamanca. Asimismo es producto de más de 10 años de pesquisa sobre el tema.

* Dr. en Historia por la Universidad de Salamanca; Encargado del área de historia oral del Archivo Histórico de la Universidad Nacional de Tucumán y docente auxiliar en la asignatura "Teoría de la Comunicación I" en la carrera de Ciencias de la Comunicación en la UNT. Especialista en la historia reciente de Tucumán con especial atención a la historia de las organizaciones de DDHH de la provincia y al movimiento obrero y estudiantil; Coordinador de la Red Latinoamericana de Historia Oral. Autor de varios artículos en revistas especializadas tanto nacionales como internacionales; Autor de libros y capítulos de libros vinculados a la historia reciente de Tucumán; Responsable de la investigación histórica y co-guionista del documental "El Tucumanazo".
} 


\title{
Voces y memorias del trauma
}

\section{Palabras claves}

memoria, derechos humanos, testimonios, trauma, historia oral, Tucumán.

\begin{abstract}
Using Oral History's methodology supposes new perspectives and challenges in the study of recent traumatic pasts. The considerations proposed by this article emerge from my own experience after having enquired in the History of Human Right's Movement in Tucumán from the compilation of it's members oral memory. When studying thoroughly dictatorship pasts and their resulting democratic transitions, we use traditional methods in order to find sources but, given the difficulty of finding written documents which held the actual facts, we must appeal to the testimony of those who have been known as social actors in that period. Using oral sources made from interviews to activists from different organizations is a challenge where temporality is central, every time that the political process in question is still open. Even with all the challenges that the person who inquires in oral history must confront, it's possibilities for studying these perspectives are very important and learning how to deal with them can contribute enormously to the investigation. In words of Alessandro Portelli, “Oral History doesn't just speak about what happened, it also tells what people would have wanted to happen and what people thought was happening". The singularity in studying Argentinian Human Right's Movement's History is the fact that this is an open process, where History isn't only recent, but also present.
\end{abstract}

\section{Keywords}

Memory, human rights, testimonials, trauma, oral history, Tucumán 
Con el testimonio se abre un proceso epistemológico, que partiendo de la memoria declarada, pasa por la archivación de los documentos y se acaba con la prueba documental. ${ }^{2}$

\section{Una perspectiva desde la historia oral}

El historiador Eric Hobsbawm afirmaba que cuando comenzó su carrera como joven historiador entrevistando a supervivientes de la Fabian Society de antes de 1914, preguntándoles cuestiones sobre su tiempo, la primera lección que aprendió fue "que ni siquiera valía la pena entrevistarles a menos que averiguase más cosas sobre el tema de la entrevista de las que ellos podían recordar. La segunda lección fue que en lo referente a cualquier hecho que pudiera verificarse de modo independiente, la memoria tendía a fallarles. La tercera lección fue que era inútil tratar de hacerles cambiar sus ideas, ya que éstas se habían formado hacía mucho tiempo y ya eran fijas. (...) Los últimos 30 o 40 años han sido la era más revolucionaria de la historia documentada. Nunca antes el mundo, esto es, las vidas de los hombres y las mujeres que viven en la tierra, se ha visto transformado de modo tan profundo, dramático y extraordinario en un período tan breve. Captar intuitivamente este hecho resulta difícil para las generaciones que no han visto como era antes el mundo"3.

Aunque concuerdo con la segunda y la tercera lección que nos ofrecía el historiador británico, no estoy de acuerdo con la primera. La experiencia de quienes trabajamos con fuentes orales nos indica que aún sin conocer profundamente el pasado que se busca desentrañar en las entrevistas, no sólo no es inútil hacerlas, sino que sirven de necesario primer paso en el camino de indagar qué ha sucedido, cómo ha sido posible y qué percepción tienen los actores sociales de aquello. Concuerdo que a veces la memoria de los entrevistados falla ya lo recordaba Tucídices-, pero aun así estimo, según mi propia experiencia, que recoger el testimonio de esos actores que han tenido una participación en el pasado se hace fundamental para captar cómo han vivido el suceso, sus puntos de vista y sus análisis, no solo de lo ocurrido, sino también de lo que quisieron que ocurriera. Es así como me parece válida la metodología que nos aporta la historia oral para el estudio de los movimientos de derechos humanos. Voy a plantear una desventaja, ciertamente la que afirma Hobsbawm, en el sentido que el investigador no ha vivido de igual manera el pasado reciente que se busca desentrañar como lo han hecho los actores sociales que han sido entrevistados; sin embargo, lo cierto es que parte de la vida de estos grupos han sido para mí reconocibles por ser

\footnotetext{
2 Paul Ricoeur, en Cuesta, Josefina (2008): La odisea de la memoria. Historia de la memoria de España, S. XX, Alianza Editorial, Madrid. P. 128.

3 Parte de la conferencia ofrecida por el historiador en la Universidad de Londres en 1993 por Eric Hobsbawm., en Hobsbawm, Eric (1998): Sobre la Historia, Edit. Crítica, Barcelona.
} 


\section{Voces y memorias del trauma}

contemporáneo de ellos, una ventaja que nos permite, sin lugar a dudas, la historia del tiempo presente.

Josefina Cuesta afirma que "el historiador faltaría a su tarea si, subyugado por las fuentes orales, sucumbiera a las sirenas de la memoria de otros y cayera en las trampas de la subjetividad. Pero se privaría de un inmenso campo de investigación si se limitara a la estrecha regla de la crítica histórica positivista y rehusara invertir la perspectiva desde un punto de vista hermenéutico: recoger, utilizar e interpretar lo que parece sospechoso en la memoria para contribuir a una historia objetiva de la subjetividad."4 Para Dominick LaCapra "el testimonio de los sobrevivientes, incluido el proceso mismo de las entrevistas, es en cierta manera un género nuevo que se está haciendo, necesariamente problemático, que tiene consecuencias en la historia oral, especialmente en las áreas de investigación más delicadas. Los historiadores todavía no han elaborado una manera aceptable de "usar" los testimonios, y las profundas diferencias entre el estado y la experiencia de las distintas víctimas, así como entre las diversas respuestas que suscitan no hacen más que complicar su tarea." 5

La decisión en torno a rescatar el pasado traumático reciente de una provincia como Tucumán, a partir de la recuperación de una "memoria oral" surge en primer lugar, de las propias limitaciones en torno a las fuentes sobre el tema y el periodo abordado. Según mi propia experiencia y tras haber hecho un exhaustivo rastreo de fuentes escritas, me di con la escasez de las mismas. La prensa local y nacional poco y nada se ha ocupado de la cobertura de las acciones de las organizaciones de derechos humanos, sobre todo durante el periodo dictatorial, donde, por lo general, acompañaron el discurso castrense del gobierno de facto haciéndose eco, en la mayoría de los casos, de los partes de prensa oficiales en lo que se refiere a la situación política local. Por lo tanto las manifestaciones, actividades, denuncias, entre otras acciones, solo pueden ser rastreadas a partir de la memoria oral de los propios militantes, quienes, cada uno a su manera, recuerdan hechos, momentos y acciones concretas. Tampoco las propias organizaciones, sobre todo las surgidas durante la dictadura y en los primeros años de la larga transición vigilada, llevaban constancia escrita de su accionar, con la salvedad de la organización de Madres de Detenidos-Desaparecidos de Tucumán quienes siguieron, durante sus primeros dos años de acción, un libro de actas, registro de sus actividades y discusiones internas. Incluso la organización mencionada no contaba con una publicación periódica como la que tenían sus pares de Buenos Aires, ni preservaba un archivo propio.

Otro tipo de fuentes menos tradicionales que los documentos escritos, como las fotografías, también son, en línea general, escasas; no encontrándose, para el periodo dictatorial, imágenes de acciones concretas que permitan hoy evaluar la

\footnotetext{
${ }^{4}$ Cuesta, Josefina (2008): La odisea de la memoria. Historia de la memoria de España, S. XX, Alianza Editorial, Madrid. P. 122

5 LaCapra, Dominick (2005): “Escribir la historia, escribir el trauma, Edit. Nueva Visión, Buenos Aires, Pp. 126 y 127.
} 


\section{Rubén Isidoro Kotler}

cantidad de militantes organizados; mucho menos documentos fílmicos como los que podemos encontrar ya en la transición. Tanto las fuentes judiciales como las registradas por una comisión investigadora de la legislatura local, surgieron además, en los primeros años de la transición, a partir de los testimonios de los familiares de afectados por la represión y de la verificación in situ, en algunos casos, de los Centros Clandestinos de Detención. Por todo lo dicho, es que planteo la necesidad de recurrir a las técnicas generadas dentro de la Historia Oral por medio de la recuperación de testimonios de militantes y dirigentes de los organismos de derechos humanos a partir de entrevistas. Sin embargo, en el marco de revisión del pasado traumático, la realización de dichas entrevistas supone una serie de problemas y al mismo tiempo desafíos a los que el historiador debe prestar cierta atención.

\section{Lo complejo del testimonio oral}

Paul Thompson afirma que "la historia oral devuelve la historia a la gente con sus propias palabras. Y al ofrecer un pasado, también ayuda a encontrar un futuro de elaboración propia (...) le da vida a la propia historia, ampliando así su enfoque. Habla de personajes no sólo extraídos entre los líderes, sino también entre la mayoría desconocida de la gente". ${ }^{6}$ Por su parte Rosa García Orellán reafirma que "los relatos de vida o historias de vida son subjetivos. No es la labor de la persona investigadora perseguir la verdad de dichos relatos, sino penetrar en el entramado de los mismos, donde se construyen y reconstruyen las relaciones sociales y, en definitiva, la cultura que está emergiendo a través de la incorporación de experiencias, que la persona muestra en su relato".7

La entrevista de historia oral se enmarca siempre en el presente: el de los entrevistados, el del entrevistador y el del tema de investigación, el cual, inevitablemente, está atravesado por este marco temporal. Los actores sociales entrevistados ya como víctimas, ya como sobrevivientes, ya como familiares de víctimas, hablan desde el presente que les toca vivir con toda la carga emocional tanto de la historia personal que les franquea, como la misma historia del presente en el que viven y en el que, sin lugar a dudas, cifran sus esperanzas o recuestan sus decepciones. Como afirman Camarena y Necoechea, "la historia oral debe rescatar la historicidad del los testimonios. El tiempo es la clave de ese sentido histórico. Corresponde al historiador rescatar el tiempo, introducirlo en la entrevista, y esto es precisamente lo que distingue su labor de otras disciplinas". Y continúan con la reflexión sobre la dimensión temporal afirmando que "el análisis del tiempo no se propone únicamente reconstruir el pasado, aunque esto sea esencial; intenta estudiar cómo se transforma la vida de la gente y cómo ésta narra tales

\footnotetext{
6 Thompson, Paul (1988): La voz del pasado. Historia Oral, Ediciones Alfons el Magnánim, Valencia. Véase también, Cuesta, Josefina, Op. Cit.

7 García Orellán, Rosa (2012): "De la oralidad a la intención biográfica”, en Llona Miren, Entreverse. Teoría y metodología práctica de las fuentes orales, Univ. País Vasco, P.77
} 


\section{Voces y memorias del trauma}

transformaciones".8 Afirmo entonces que el tiempo de la entrevista es distinto al tiempo de la narración y ambos deben conjugarse en la compleja trama que se procura reconstruir.

Concluyendo la idea sobre la cuestión temporal, vuelvo a Camarena y Necoechea cuando expresan que "aunque el tiempo siempre está en presente en el acontecer cotidiano, no es un elemento consciente en el curso de la entrevista, ni para el estudioso ni para quien cuenta su vida." Sin embargo, afirman que "la forma en que se maneja el tiempo revela la concepción que de éste tienen ambos protagonistas". ${ }^{9}$ O como lo refiere Pablo Pozzi 10 "el recuerdo (...) se encuentra en una zona confusa y contradictoria que combina percepciones actuales con las pasadas y con la experiencia vivida (...) Debido al hecho de que muchos se sienten derrotados, las frustraciones, el dolor y la sensación de pérdida fueron expresadas contradictoriamente con la alegría, la reivindicación del momento (...) Aquí los testimonios dicen mucho más de lo que dicen, verdad que suena de perogrullo, pero que el investigador debe tener en cuenta, pues no solo nos habla del pasado, sino del propio presente."11

Al hablar de los cambios sociales, Williams explicaba que podían ser de dos maneras: por una parte son cambios de "presencia" y por la otra, "no necesitan esperar una definición, una clasificación o una racionalización antes de ejercer presiones palpables y de establecer límites efectivos sobre la experiencia y sobre la acción".12 Según Williams, tales cambios pueden ser definidos como cambios en la "estructura del sentir", por lo tanto, y siguiendo al sociólogo inglés, debemos procurar establecer "los significados y valores tal como son vividos y sentidos activamente; y las relaciones existentes entre ellos y las creencias sistemáticas o formales".13 Una alternativa a las estructuras de sentimiento, sería el de las estructuras de la experiencia. Al definir los elementos del testimonio como una estructura, lo podemos observar entonces como "un grupo de relaciones internas específicas, entrelazadas y a la vez en tensión". Sin embargo, como bien indica Williams, "estamos definiendo aquí una experiencia social que todavía se halla en proceso, que no siempre es reconocida como social, sino como privada." 14

\footnotetext{
8 Camarena, Mario y Necoechea Gerardo (2008): Continuidad, ruptura y ciclo en la historia oral, en Pozzi y Necoechea: Cuéntame cómo fue, Edit. Imago Mundi, P. 55

${ }^{9}$ Ibídem

10 Pozzi hace referencia aquí a las entrevistas que realizó a militantes del PRT-ERP, sin embargo su análisis nos sirve ya que nos acerca a la problemática del tiempo de la entrevista. Sin lugar a dudas la experiencia de entrevistar a militantes de partidos revolucionarios de los 70 es muy distinta a la de entrevistar a familiares de víctimas de la dictadura, pero hay un nexo temporal que debe ser analizado y que es común entonces a todas ellas. Esta valoración temporal del momento de la narración (no del momento narrado) es una tarea que todo historiador debe procurar si desea trabajar con fuentes orales.

11 Pozzi, Pablo (2004) Por las sendas argentinas. El PRT-ERP, la guerrilla Marxista. Imago Mundi, Pp. 33 - 34.

12 Williams, Raymond (2000): Marxismo y Literatura, Op. Cit., Pp. 150 a 159

13 Ibídem.

14 Ibídem.
} 


\section{Rubén Isidoro Kotler}

Al acercarnos al estudio de movimientos sociales que no han sido masivos, como el que conforman las organizaciones de derechos humanos de Tucumán y que han tenido un objetivo específico al hacer su aparición en la esfera pública, las entrevistas orales nos permiten tener un conocimiento más cabal de su propia existencia y nos ayuda a situar el relato en el tiempo, tanto en el tiempo vivido y experiencial como en el propio tiempo presente del cual surge el relato.

La contemporaneidad de los sujetos participantes permite analizar no solamente los hechos que muestran algunas evidencias escritas y de otra índole, sino también la percepción que de los acontecimientos tienen los entrevistados. ${ }^{15}$ La entrevista oral contribuye a que el historiador pueda acercarse a sujetos participantes que no tuvieron suficiente representación en los medios escritos, tanto periodísticos como en otras fuentes oficiales. ${ }^{16} \mathrm{En} \mathrm{mi}$ investigación he buscado indagar por medio de las entrevistas a los militantes, no sólo qué ha ocurrido y cómo ha sido posible el surgimiento de estos grupos sociales, sino también qué percepción tienen o han tenido los testigos ${ }^{17}$ de lo ocurrido, qué quisieron que ocurriera y qué fue lo que realmente ocurrió, como lo plantea Alessandro Portelli. ${ }^{18}$ He buscado establecer las pautas de la experiencia vivida, analizando por medio de los testimonios los cambios producidos procurando encontrar esas estructuras del sentir de las que habla Williams. Gabriela Águila y Cristina Viano sintetizan el problema del trabajo con las fuentes orales y la distinción de éstas con las fuentes escritas al afirmar que "la historia oral tiene un punto de partida muy distinto al de quienes trabajan exclusivamente con fuentes escritas. La práctica de la historia oral comporta una dimensión personal, subjetiva, afectiva, que se despliega en el trabajo de campo y que supone un intercambio constante y un persistente movimiento de roles entre los sujetos involucrados en él, que lo diferencian cualitativamente del trabajo con "fuentes muertas". ${ }^{19}$ Como afirma Rosa García Orellán, "como investigadores debemos tener la capacidad de

\footnotetext{
${ }^{15}$ Véase en este tema Chartier, Roger (1992): El mundo como representación. Historia cultural: entre práctica y representación, Edit. Gedisa, Barcelona. Para Pablo Pozzi también la representación que los actores sociales se hacen del proceso vivido resulta indispensable para la reconstrucción del relato histórico.

16 Nótese que hoy en día, toda organización tiene su medio de prensa. La aparición de Internet a fines de los años '90 y la popularización de su uso en los últimos años, ha permitido y permite a organizaciones, como las aquí estudiadas, tener su propio espacio de difusión. Un claro ejemplo de esto son los sitios web de las organizaciones de derechos humanos en la que dejan constancia de cada actividad o discurso desde lo visual, lo textual o el hipervínculo, enlazándose unas con otras. El periodo abordado en este trabajo, sin embargo, no cuenta con tal facilidad al acceso documental como lo vengo explicando desde el comienzo.

${ }^{17}$ Hablo de testigos como los entiende Jelín en una de las acepciones en el campo de la historia oral: aquellas personas que han vivido una experiencia y pueden en un momento posterior narrarla, "dar testimonio". Veáse Carnovale, Lorenz y Pittaluga Comps. (2006): Historia, Memoria y Fuentes Orales. Edit. CEDINCI, Buenos Aires.

${ }^{18}$ Portelli, Alessandro, Lo que hace diferente a la historia oral, en Schwarzstein, Dora Comp. (1991): "La Historia Oral". Colección, Los fundamentos de las Ciencias del Hombre. Centro Editor de América Latina. Buenos Aires.

${ }^{19}$ Aguila Gabriela y Cristina Viano; "Las voces del conflicto: en defensa de la Historia Oral", en Cristina Godoy (editora) Historiografía y Memoria Colectiva. Tiempos y Territorios; Miño y Dávilo, Madrid/Buenos Aires, año 2002. Pág.247.
} 


\section{Voces y memorias del trauma}

extrañamiento. Ésta constituye una forma de curiosidad que se despierta cuando se descubre que las vidas de las personas, sus formas de entender la realidad y de ponerla en práctica, son diversas." 20

Si bien es posible confiar en el relato de un entrevistado, algunas fechas, nombres o sucesos caen en el olvido, entran en contradicción o se vuelven incomprensibles, sobre todo cuando han transcurrido tantos años desde los comienzos de la militancia. Lo que algunos científicos sociales han analizado de las entrevistas y sus resultados al hablar de la memoria, han centrado su atención en su contrapartida, el olvido, y esto se hace evidente en los diálogos. De aquí la importancia de rastrear nuevas evidencias en otro tipo de fuentes más tradicionales para una constatación de lo que surge del relato de los testimonios. Como esos olvidos o las distorsiones involuntarias en los relatos de los entrevistados pueden conducirnos al fracaso de la investigación, es pertinente pensar en un proyecto que contemple los relatos orales como un desafío. Como afirma Galasso "no se trata de un nuevo evangelio documental que ha de ser apartado, sino de la necesidad de integrarlo inmediatamente con su código crítico". 21

La entrevista de Historia Oral es "un producto intelectual compartido mediante el cual se produce conocimiento".22 El objetivo de la entrevista es el recuerdo del entrevistado, es uno de los "trabajos de la memoria", y, tal como lo señalaba Schwarzstein, "es la intervención del historiador y lo que éste pone en términos de preguntas (...) lo que sirve como impulsor para la producción de información histórica". ${ }^{23}$ También ésta ha sido una preocupación del Instituto de Historia del Tiempo Presente de París, tal como lo recoge Cuesta donde "la interacción historiador-testigo es una inquietud metodológica cultivada asiduamente: confrontar sistemáticamente los análisis de los historiadores a los testimonios de los grandes actores, (...) esta confrontación ha mostrado que es muy fuerte la curiosidad recíproca entre historiadores y testigos: la confrontación del documento y del testimonio..."24

Mi propio trabajo partió de un cuestionario semi-estructurado, adaptado a las necesidades de cada entrevistado según la organización a la que ha pertenecido, teniendo en cuenta además quiénes de esos entrevistados se han alejado de la militancia, y quiénes han continuado ocupando un lugar clave dentro del movimiento de derechos humanos al momento de ser interrogados. Aquí es el historiador/entrevistador quien ha dirigido la entrevista de acuerdo al interés buscado desde donde ha sido posible construir el objeto de análisis. He buscado

20 García Orellán, Rosa (2012): De la oralidad a la intención biográfica, en Llona, Miren (coord.): Entreverse. Teoría y metodología de las fuentes orales, Univ. Del País Vasco, P. 74.

21 Galasso, Giuseppe, Nada más que historia, Op. Cit. Pp. 270 a 273.

22 Schwarzstein, Dora Comp. (1991): "La Historia Oral". Colección, Los fundamentos de las Ciencias del Hombre. Centro Editor de América Latina. Buenos Aires. P. 12.

23 Ibídem.

${ }^{24}$ Cuesta, Josefina: “La Historia del Tiempo Presente: estado actual de la cuestión”. En Estudia Histórica, Historia Contemporánea, Vol. 4, ediciones de la Universidad de Salamanca, P. 234. 


\section{Rubén Isidoro Kotler}

confeccionar un cuestionario base general y sobre ese cuestionario he elaborado las preguntas propias para cada integrante de los organismos. Sin embargo no he descartado la posibilidad de realizar más de un encuentro con los entrevistados, por lo que algunos testimoniantes han aportado sus experiencias en más de una oportunidad. Sobre esta cuestión he seguido entonces las recomendaciones del propio Paul Thompson quien sugiere que "la mejor manera de empezar trabajos puede ser la realización de entrevistas exploratorias, estructurar un campo y recoger ideas e información".25 Siguiendo este camino, el mismo Thompson asegura que es posible debilitar un problema y ubicar los recursos para resolverlo. Es así como para mi pesquisa tanto la entrevista general de recopilación como la entrevista piloto han resultado de mucha utilidad. ${ }^{26}$ "Si las fuentes orales pueden suministrar realmente información fiable, tratarlas simplemente como un documento más es ignorar su especial valía en tanto que testimonio subjetivo y hablado". ${ }^{27}$ Visto desde esta perspectiva, la cuestión aquí planteada ha sido el escuchar la voz de los sectores que tiempo atrás fueron subalternos frente a los sectores dominantes. 28

Como asevera Portelli, no existen fuentes orales falsas. Juegan en los testimonios la imaginación, el simbolismo y el deseo. ${ }^{29}$ El olvido o el cambio en la información brindada a partir de testimonios orales, puede ser interpretado de maneras diferentes, si se realiza un estudio al interior de los relatos mismos. Se olvida o se oculta información por cuestiones que pueden tener que ver con estados emocionales o simplemente por alguna intencionalidad que podría o no detectarse. En este mismo sentido y frente a quienes aducen que los testimonios orales son menos confiables que las fuentes escritas, es posible demostrar que las segundas pueden ser modificadas o resultar apócrifas y por lo tanto dejan de ser creíbles dentro del contexto de una investigación histórica como la presente. Hay historiadores e historiadoras que desprecian el uso de los testimonios orales olvidando que muchas de sus fuentes son fruto precisamente de eso, de testimonios orales que fueron transcriptos, como puede ser el caso de los registros de un debate parlamentario o los testimonios recogidos de una entrevista publicada en un medio gráfico. ${ }^{30}$ De la misma manera, algunas fuentes escritas, son justamente producto también de un testimonio oral. ${ }^{31}$ Al mismo tiempo los

\footnotetext{
25 Thompson, Paul, Op. Cit.

26Ibídem.

27 Ibídem.

${ }^{28}$ Dada la incorporación de algunos militantes del campo de los derechos humanos a estructuras del actual gobierno, los que se reconocían como subalternos al poder dominante en los años dictatoriales o de la transición, hoy no solo comulgan con los poderes establecidos sino que los acompañan ya que ven en ellos la voluntad de contribuir al cumplimiento de los objetivos históricos de verdad y justicia.

${ }^{29}$ Portelli, Alessandro, Lo que hace diferente a la historia oral, Op. Cit.

30 Ibídem.

${ }^{31}$ Me refiero en concreto a las fuentes judiciales o bien a otro tipo de documentos en los que se reproduce sin más el testimonio de quien testifica "algo".
} 


\section{Voces y memorias del trauma}

testimonios surgidos a partir de las entrevistas Sirven incluso también para corroborar algunos de los datos aportados por las fuentes escritas encontradas.

Asimismo, determinados procesos han contribuido a disparar los recuerdos de los entrevistados. Lo que Vezzeti menciona como "soportes materiales de la memoria" desde los objetos personales o a la realización de la entrevista en los lugares donde han transcurrido ciertos sucesos ${ }^{32}$ para ayudar a develar ciertos recuerdos en lo que Thompson, en concordancia recomienda, cuando habla de la utilización de "diversas ayudas para la memoria"33 o como las denomina Gerard Namer los "despertadores de la memoria". En este sentido algunos entrevistados hicieron uso de sus archivos personales para recordar algunas de las anécdotas narradas: desde carpetas de recortes de periódicos celosamente custodiados, hasta documentos privados de las organizaciones, me han servido no solo para triangular aquí el relato oral con el papel escrito, sino también como verdaderos despertadores de memoria. Cartas, recortes, fotos y objetos personales han servido en más de una entrevista para disparar un recuerdo de un suceso ya lejano en el tiempo, material que ha sido cedido y que ha servido también de documento para corroborar posteriormente si lo narrado era cierto o no.

\section{Los cinco componentes del relato testimonial}

Josefina Cuesta, afirma que la entrevista "es fruto de la superposición y combinación de las diferentes memorias, de las que el sujeto es portador: la memoria personal, social, colectiva y dentro de ésta (...) la familiar, de clase, nacional, política o ideológica". ${ }^{34} \mathrm{Al}$ adentrarnos en las historias particulares de los militantes de derechos humanos, asistimos a la rememoración de las actuaciones individuales pero al mismo tiempo colectivas. Pero ¿qué hay dentro de cada testimonio de particular? Citando a Ricoeur y Dulong, Cuesta reafirma los componentes esenciales del testimonio, sintetizados en cinco $^{35}$ :

1) "De la aseveración del hecho a la certificación de su autenticidad: "Yo estaba allí”."

Este componente es fácilmente ubicable en los testimonios. Por lo general, encontramos que la mayoría de los relatos utilizan la primera persona, bien del singular, cuando narran una acción individual, o bien del plural, cuando se posicionan dentro de una acción acometida por la organización a la que pertenecían (o pertenecen). La mayoría refiere a hechos concretos de sus vivencias personales. Sucede, incluso, que alguno de los entrevistados ha resguardado consigo una carpeta con documentos personales entre los que se destacan recortes

\footnotetext{
${ }^{32}$ Hugo Vezzeti: “Un Mapa por trazar”, en Revista Puentes. № 1 - Agosto 2000.

${ }^{33}$ Thompson, La Voz del pasado. Historia Oral, Op. Cit.

${ }^{34}$ Cuesta, Josefina (2008): La odisea de la memoria. Historia de la memoria de España, S. XX,

Alianza Editorial, Madrid. P. 128.

35Ibídem.
} 


\section{Rubén Isidoro Kotler}

de prensa de la época y van rememorando, a la par que muestran el "documento" donde aparece el registro, que, efectivamente, ellos han sido partícipes, ya porque se los menciona, ya porque aparecen en la fotografía que acompaña a la nota periodística. Estos archivos resultan al mismo tiempo como los soportes materiales de la memoria a los que refiere Hugo Vezzetti ${ }^{36}$, pues en concreto una fecha o un lugar termina de precisar el "yo estaba allí" y permite dar mayor veracidad al propio testimonio al tiempo que califica al testimoniante como "válido", pues quién mejor que él, que ha estado allí para certificarlo. Por otra parte volvemos a insistir en que no nos quedamos con la reafirmación de la presencia y la necesidad de revisar otras fuentes que nos permitan corroborarla.

2) "La especificidad del testimonio: "Yo lo vi"."

El haber estado o el haber sido "testigo ocular"37 hacen que necesariamente el relato pase por la prueba de la comprobación y la aseveración. Esa primera persona se transforma en singular cuando lo individual supera lo colectivo. Igualmente todo relato en primera persona supone la existencia del testigo ocular ya que el haber estado en un determinado hecho o haber sido partícipe del mismo convalida el conjunto del relato más allá de las contradicciones internas del mismo, más allá de ciertas omisiones o equivocaciones. El testimoniante se ubica inmediatamente en el lugar de la acción y transmite, lo más fielmente que puede, no solo lo que ha visto, sino su propia experiencia subjetivada, claro está, en la acción de la que ha sido partícipe.

3) "La autodesignación y acreditación: "Puedes creerme”.

Este componente no suele hacerse explícito, pues toda entrevista es, por lo general, buscada por el historiador y "pautada" entre dos partes. En mi caso, he llegado a mis "testimoniantes" ubicándolos personalmente, en general, estableciendo implícitamente un pacto de credibilidad. Siempre partimos de un contrato tácito en el que decidimos creer al entrevistado. De todas formas, hay que tener presente que siempre que el entrevistado narra un suceso en particular busca la apoyatura material para que el relato, que podría ser "no creíble", se torne veraz. De igual forma, conviene insistir en que más que la veracidad del relato, lo que nos importa en primer lugar, es la percepción que el testimoniante tiene sobre el pasado. Los despertadores de la memoria una vez más se vuelven imprescindibles cuando el relato aparece increíble.

4) "Ante la posibilidad de la sospecha, confrontación de testimonios: "Pregunta a otros"."

Cuando la auto-acreditación planteada en el punto anterior es puesta en duda, asoma en el entrevistado la confrontación con sus pares. Al preguntar a otros o al apoyarse en la posibilidad de la verificación sobre el dato de un lugar o una

${ }^{36}$ Vezzetti, Hugo (2000): Un Mapa por trazar, en Revista Puentes. $\mathrm{N}^{\circ} 1$.

${ }^{37}$ En los términos expuestos por Josefina Cuesta tomados de Dulong. 


\section{Voces y memorias del trauma}

fecha que no se recuerda, los entrevistados, salvo excepciones, presumen la posibilidad de que el entrevistador pueda preguntar a "otros testigos". Vale aquí el ejemplo de una de las entrevistadas que había puesto como condición para dar su testimonio, hacerlo con un par que corroborara o contrastara su testimonio. Incluso, hubo entrevistas que pude hacerlas entre dos militantes de una misma organización entrevista que se vio enriquecida, inclusive, con la discusión entre los relatos sobre la propia percepción del proceso vivido. ${ }^{38}$

5) "La credibilidad y la fiabilidad del testimonio: "Su mantenimiento a lo largo del tiempo"."

Este último componente es objeto de discusión entre los historiadores orales. Hay quienes sostienen que el sostenimiento del relato en el tiempo, lejos de tornarlo creíble, debe hacernos cuestionarlo, pues puede ser una mera construcción del entrevistado que repetirá durante años para convencerse que ha sido así, como él o ella lo narran, y no de otra manera. En mi opinión, y según veremos en el caso de uno de los testimoniantes, su relato no sólo se ha sostenido, sino que puede verificarse en el tiempo ¿Equivale esto a la transformación de su relato en veraz?

Cito a continuación dos ejemplos de todo lo antes dicho con los testimonios de Felicidad Carreras ${ }^{39}$ y Carlos Soldati. ${ }^{40}$

\footnotetext{
${ }^{38}$ Me refiero en concreto a las entrevistas con Julia Vittar y María Coronel, ambas militantes de la organización HIJOS, como así también a la entrevista realizada a Atilio Castagnaro y María Angélica Mazzamutto, de la organización Asamblea por los Derechos Humanos de Tucumán. Las entrevistas colectivas tienen la ventaja de permitir la apoyatura del recuerdo de unos y otros entrevistados. Cuando, en mi caso, comencé con las primeras pesquisas sobre la historia de las Madres de Detenidos Desaparecidos de Tucumán, recurrí a los talleres de Historia Oral que me permitieron reunir a más de una integrante de la organización, entrevista que con sus pros y sus contras, fueron muy provechosas también en este sentido, el de la credibilidad sostenida por la aseveración de cada testimonio en la afirmación del colectivo.

${ }^{39}$ La entrevista con Felicidad fue realizada en los primeros meses de 2008 y el caso de su hermano desaparecido, Juan Carreras, es emblemático. Juan Carreras debía presentarse a rendir el 16 de septiembre de 1976 un examen final. Juan debía encontrarse momentos antes del examen con Enrique Sánchez, un amigo y compañero de carrera. Sin embargo Sánchez fue secuestrado la noche anterior al examen y el encuentro entre los amigos no se produjo. Sin embargo la desaparición de Juan involucra al propio Enrique. El "grupo de tareas" que secuestró a Juan usó de señuelo a Sánchez, llevándolo en un coche al momento de encontrarse con Juan. Desde fuera, Juan saluda a Enrique sin que éste le devolviera el saludo. Juan estaba entonces ya "señalado" por su amigo. Carreras entró a rendir sin saber por qué su amigo no le había saludado. Promediando el examen tres hombres ingresan en la sala y preguntan si se encontraba allí Juan Carreras. La Doctora Elsa Brauckman, quien estaba tomando el examen, respondió afirmativamente. De allí en más todo cambió para Juan. Carreras fue el último estudiante en salir de la sala. Desde el mismo momento en que entraron los hombres a buscarle Juan comenzó a dibujar líneas en el papel del examen. Al salir de la sala, el joven pidió ayuda al profesor titular de la Cátedra, el Dr. Francisco Barbieri quien se encontraba en el pasillo del edificio universitario. Barbieri no atinó a hacer nada por el estudiante, quien acto seguido fue sacado de la facultad por los hombres que le buscaban.

${ }^{40}$ La entrevista a Carlos Soldati ha sido realizada el 1 de diciembre de 2007, días antes de asumir la presidencia de Argentina la esposa del ex presidente Néstor Kirchner. Por este motivo en varias oportunidades, el entrevistado manifiesta abiertamente cierta esperanza que la continuidad en la línea sucesoria en la conducción política del país lleve a buen término
} 


\section{Rubén Isidoro Kotler}

\section{El testimonio de Felicidad}

Felicidad Carreras militó desde la desaparición de su hermano, Juan Carreras, en la organización de Familiares de Detenidos por Razones Políticas. El 19 de junio de 1995, dos meses antes de las elecciones presidenciales que encumbrarían a la gobernación de Tucumán al ex dictador Antonio Domingo Bussi, las organizaciones de Derechos Humanos locales organizaron un juicio simbólico con el objetivo de influir en la opinión pública y evitar lo que parecía inevitable, el triunfo del represor. Si bien Felicidad no participó activamente, guarda entre sus recuerdos una acción que merece ser destacada:

Pregunta: ¿Cómo fue lo del Juicio Ético?

Felicidad Carreras: «Sí, que fue toda una historia que te deben haber contado, que lo hacíamos en un lado, que lo hacíamos en otro lado, bueno por fin se lo hizo en el aquel club chiquito, pero una cosa muy importante que cuando lo veía a Carlos Zamorano, me acordaba porque él fue uno de los jueces, y, pero yo no participé ni como testigo ni como nada porque estaba muy bien organizado, fue una cosa relativamente corta, me acuerdo que Carlos Soldati, vos sabes que no me acuerdo quien más... Gerardo Romano me acuerdo que estuvo presente, estuvo presente porque yo lo invité, ¿te contaron? Fue muy gracioso.

Pregunta: Cuénteme, quiero que usted me lo cuente...

Felicidad: Muy gracioso. Resulta que yo me entero por el diario que estaba Gerardo Romano poniendo una obra de teatro acá en el teatro Alberdi, si no me equivoco, entonces digo: "a este tipo hay que invitarlo", entonces hago una notita, que decía: "Gerardo, soy fulana de tal, no me acuerdo exactamente, mañana en tal lugar, no me acuerdo en lugar porque iba a ser en este club que queda pasando la avenida sarmiento...

\section{Pregunta: ¿Estudiantes?}

Felicidad: Sí, creo que era ahí... "vamos a hacer un juicio ético a Bussi como "sé cómo piensas" una cosa así te invito, presente Mimi Carreras". Me voy en el auto de una amiga con el sobre cerrado, lo dejo, bueno pasa. Vos sabes que yo el día ese del juicio eran tantas cosas que ni me he acordado de Gerardo Romano, sinceramente a mí él me encanta como actor, como hombre; proviniendo hacia el final, el locutor que no me acuerdo quien era, dice: "Acá contamos con la presencia (...)", bueno estaba David Viña, todos los que habían venido, el padre Farinello, Rosichner, el Perro Santillán, y en un momento dice, "contamos con la presencia del actor Gerardo Romano"; estábamos en un grupo de gente y empiezo a mirar, a buscarlo, cuando lo veo estaba teñido de rubio, de pelo claro, no me olvido, era una cosa rarísima, en medio de toda la gente cruza y se sube al escenario, se para en el escenario y lo primero que dice: “QQuién es Miní?” ... dicen mis amigas que me tuvieron que hacer una camita, casi me desmayo de la emoción y yo le gritaba “iyo!, ¡yo!” y me dice él

algunos de los procesos judiciales contra los responsables de la dictadura. Nuevamente nos merece la pena ubicar en contexto la entrevista. Ocasionalmente he podido cruzarme con Soldati y nunca ha dejado de manifestar su satisfacción por los avances en materia judicial en la provincia, por lo que tras la desilusión de largos años de militancia, hoy ve con expectativas los juicios que se llevan a cabo en la provincia. 


\section{Voces y memorias del trauma}

"gracias por invitarme, porque por eso estoy acá" una cosa así, por supuesto él habló unas cuantas palabras muy lindas y después me acerqué al escenario para saludarlo cuando bajaba, le dije: "cuánto te agradezco..."

En el transcurso de la investigación pude obtener una copia de una filmación de tipo "casera" del Juicio Ético. En un fragmento de la misma la cámara enfoca un primer plano en el que aparece el actor Gerardo Romano, mencionado por Felicidad y en el que, antes de decir unas palabras en apoyo al juicio simbólico, efectivamente pregunta por "Mimí" y le agradece públicamente la invitación. El relato de Felicidad es apenas una de las tantas anécdotas que ella misma cuenta sobre todo cuanto hizo en el marco de su militancia, acciones todas tendientes a recuperar a su hermano primero y por la persecución de la verdad y la justicia ya en los años de la transición. Varios fragmentos de sus testimonios parecen inverosímiles, como la anécdota misma del Juicio Ético, sin embargo habiendo triangulado las fuentes mencionadas, la narración de Felicidad se vuelve creíble. Si bien he cierto que yo he creído todo lo narrado por Felicidad, la constatación de al menos uno de sus relatos, me permite pensar que en la credibilidad de su totalidad. Felicidad menciona que el actor en cuestión aparecía en escena teñido de rubio. Lejos de la realidad que se observa en el video, Romano se ve con su cabellera natural color castaña ¿Indica esto que el relato de Felicidad se torna inverosímil? Desde mi óptica no, pues la anécdota de conjunto se verifica y en todo caso, habiendo transcurrido más de 15 años, ciertos aspectos de la memoria tienden a fallar o se desdibujan en un relato al que el testimoniante "tiñe" con sus subjetivaciones. No está en cuestión aquí si Romano se presentó teñido de rubio o no, sino la percepción que Felicidad tiene de toda su propia historia en la búsqueda de su hermano desaparecido. Podemos creer en el relato de Felicidad sin el cual, por ejemplo, jamás hubiéramos podido conocer la historia de los tres "belichos ${ }^{41 "}$ desaparecidos. Ante el hecho traumático vivido por la desaparición de su hermano secuestrado, Felicidad recupera de su memoria no solo aquellos fragmentos de la historia en los que vive la tragedia en forma de derrotas políticas, sino también que afloran con orgullo aquellas acciones que contribuyeron al desarrollo de lo colectivo en el que ha participado. ${ }^{42}$

\footnotetext{
${ }^{41}$ Belichos es el gentilicio de los habitantes de la localidad de Belén, en Catamarca, de donde era Juan Carreras. Además de Carreras, han sido secuestrados otros dos ciudadanos de Belén, Oscar Gerván, ex sacerdote vinculado al tercer mundismo y Yolanda Borda, también estudiante de Bioquímica como Juan. El caso Borda también es emblemático pues es el único secuestro que se constata en la misma localidad de Belén donde se encontraba la joven. Tanto Juan como Yolanda formaban parte del cuerpo de delegados de la Facultad de Bioquímica cuyos integrantes se encuentran desaparecidos.

${ }^{42}$ Cabe mencionar que al escribir el presente artículo, ya ha transcurrido el juicio por la Mega Causa del Arsenal Miguel de Azcuénaga, donde ha sido visto por última vez Juan, el hermano de Felicidad y ella ha prestado declaración testimonial como querellante en la causa.
} 


\section{Rubén Isidoro Kotler}

\section{Los cuatro testimonios de Carlos}

Soldati vive en la localidad de Simoca, ubicada en el sur de la provincia de Tucumán, en una finca que pertenecía a sus padres. Tiene a dos de sus hermanos secuestrados y desaparecidos, habiendo sido él mismo secuestrado y objeto de torturas. Desde la desaparición de su segundo hermano, en 1977, ha sido un activo militante en tres de los organismos de derechos humanos de la provincia. Los comienzos de su militancia se ubican en Familiares de Detenidos por Razones Políticas, pasando un tiempo por Madres de Plaza de Mayo desde fines de $1981 \mathrm{y}$ finalmente ha sido uno de los fundadores de la Asamblea Permanente por los Derechos Humanos en Tucumán, el 24 de enero de 1984. He podido entrevistar a Carlos a fines de 2007, unos meses antes del primer juicio contra Bussi, en la causa por la desaparición del ex senador Guillermo Vargas Aignasse. ${ }^{43}$ Esta entrevista se dio en el contexto del punto culmine de las llamadas políticas de derechos humanos de la administración del ex presidente Kirchner. Como muchos otros activistas del movimiento, Soldati recuerda casi con lujos de detalles las circunstancias del secuestro de su familia, incluidas las del propio. Los cuatro testimonios que cito en el siguiente cuadro se corresponden, en orden cronológico: el primero, recogido por el periódico local, data del 12 de febrero de 1984, cuando la APDH local hacía su presentación pública y Carlos narraba su propio secuestro; el segundo, a instancias de un Juicio Ético contra Bussi ${ }^{44}$ el 19 de junio de 1995, donde fungía de testigo y narraba con precisión las mismas instancias de su secuestro; el tercero de los testimonios se corresponde con la entrevista que le hice el primero de diciembre de 2007, en su hogar; el cuarto es el testimonio que prestara Carlos como testigo querellante por su secuestro en el juicio de Jefatura, el 31 de marzo de 2010.

\section{Los testimonios de Carlos Soldati}

$\begin{array}{lll}\text { AÑO DEL } & \text { LUGAR } & \text { TRANSCRIPCIÓN } \\ \text { TESTIMONIO } & \text { DEL TESTIMONIO } & \end{array}$

Fui secuestrado en la madrugada del 28 de septiembre de 1976 por un grupo fuertemente armado que irrumpió en la casa de mis padres. Se movilizaban en un auto y un furgón dentro del cual me arrojaron mientras un camión del ejército

$\begin{array}{ll}12 \text { de febrero de } & \text { La Gaceta de } \\ 1984 & \text { Tucumán }\end{array}$
supervisaba el operativo.

(Narró luego que fue trasladado a un

\footnotetext{
${ }^{43}$ Juicio que se ha consubstanciado a mediados de 2008
}

${ }^{44}$ Sobre este Juicio volveré en otro capítulo de esta tesis. 


\section{9 de junio de 1995 Juicio Ético a Bussi}

\section{campo de concentración cercano a Famaillá)}

Había un considerable número de personas que eran traídas de noche. La tortura era allí permanente. A la noche siguiente fui trasladado en un camión del Ejército hasta la brigada de investigaciones, en Avenida Sarmiento y Muñecas, donde funcionaba otro centro clandestino. Me dieron el número $102 \ldots$

El 28 de septiembre de 1976, a eso de las dos y media de la madrugada un grupo armado de civil, con la cara cubierta, identificándose como de la policía, entra en la casa de mis padres, en Manuela Pedraza, cerca de Simoca. La luz se enciende, yo me siento sobre la cama y los veo subir por la escalera, con armas largas, cortas, linternas, me preguntan a los gritos por mi nombre, y desde abajo contestan "ese es"... yo estaba aterrado. "Hay un error, ¿qué pasa, qué pasa?" El que dirigía el grupo, que si estaba con la cara descubierta y me pone la pistola en la cabeza y me dice que me calle, me amenaza con matarme, me tira los anteojos y me saca arrastrando de mi casa. Antes que me pongan la capucha, alcanzo a ver a un auto al frente de mi casa y un poco más adelante me tiran en el piso y me suben a un camión del ejército, con el sonido característico de los (...) que supervisaba el operativo.

Cuando me tiran en el piso de la camioneta furgón, veo que hay otra persona ahí tirada. Tengo la certeza de que ese muchacho era Pedro Pablo Rodríguez, que después me entero que unos minutos antes había sido secuestrado por el mismo grupo en Simoca.

La camioneta se toma en dirección rumbo al norte a toda velocidad, después de unos minutos, gira hacia el oeste por el único camino de tierra que conduce hacia Famaillá y después de unos minutos llego a destino, me bajan y me introducen en lo 


\section{Primero de \\ Entrevista de \\ diciembre de 2007 \\ Historia Oral}

que es un corredor ancho y en una galería cerrada me tiran al piso. Pude observar ahí un número considerable de personas maniatadas, vendadas, que se quejaban. Enseguida gritos, corridas, ruidos de motores, pregunto qué pasa, "van a buscar más gente", me dicen (...)

(...) ese mismo año, el 28 de septiembre me sacan de esta casa, aquí, de Manuela Pedraza, un grupo armado, a eso de las dos de la mañana, que se desplazaban en un vehículo de la policía, ellos se identifican verbalmente como de la policía, estaban de civil, mis padres estaban aquí, les abren la puerta y bueno... yo duermo en un altillo, veo que se enciende la luz, me incorporo sobre la cama y los veo subir y a los gritos me preguntan cómo me llamaba y entonces me sacan arrastrando, me tiran los anteojos, y... antes de que me colocaran la capucha veo un automóvil de la policía de aquí a 100 metros, sobre la entrada de la casa y me tiran en el baúl, en el piso de un furgón donde había otra persona y partimos a gran velocidad. Después un vecino cuando yo aparezco después, me comenta que un camión del ejército, con el ruido característico de los (...) que ahí desde la ruta supervisaba el operativo. Y bueno, dicen, una frase: "demasiado bueno es Videla, ya no quiere más muerte, pero si están en la joda (ese es el término que usaban) por mucho tiempo no se va a saber de ustedes".»

Pregunta: ¿Eso les decían a ustedes dos? A mí y el otro escuchaba, yo ni sabía quién era. Después me entero, cuando yo aparezco, de que ese muchacho había sido secuestrado minutos antes, en Simoca, a cuatro kilómetros de aquí, y era Pedro Pablo Rodríguez. Bueno, yo creí que me mataban, que me hacían descender del vehículo y me ametrallaban aquí a unos cuantos kilómetros, pese a que uno está vendado y tirado, pero por el movimiento del cuerpo sé que el vehículo toma 
31 de marzo de 2010 dirección norte y luego de unos minutos dobla hacia la izquierda, (...) levantan a otro en el camino también, secuestran a otra persona, ya éramos tres y llego a un lugar que después ubico como Famaillá, pero me bajan como a una especie de galería cubierta donde había muchas personas, así, vendadas y maniatadas (...)»

El 28 de septiembre del año 1976, a eso de Juicio de Jefatura las dos y media de la madrugada, un grupo numeroso, entre 15 y 20 personas, llegan a la casa de mis padres, en Manuela Pedraza, cerca de Simoca, "¡abran la puerta, es la policía!”, gritan; mi mamá, asustada, les abre la puerta de la galería del fondo y entran, con armas, con linternas, con la cara cubierta con medias y pañuelos, se notaba que eran personas jóvenes, menos una, que actuaba a cara descubierta y con una pistola en la mano, era el que dirigía el grupo, recorren las habitaciones preguntando dónde está Soldati, el que estudia, de pronto descubren las escalera del altillo, prenden la luz, el golpe de luz me despierta, me siento sobre la cama y los veo subir por la escalera. Mientras me alumbraban con sus linternas, a los gritos me preguntaban cuál era mi nombre y qué hacía, varias veces. Observo que un muchacho con la cara cubierta con un pañuelo, sube por la escalera, los otros dicen "¿Sabes quién es él? Un asesino profesional contratado para matar", desde abajo, el que dirigía el grupo pregunta por mi nombre, le dicen "Carlos Soldati”, “ Ese es!", yo estaba aterrado. Me pongo a gritar “¡Hay un error, no puede ser!”, el que dirigía el grupo sube por la escalera y me pone la pistola en la cara diciendo "Callate que te mato", me bajan, y en el living los veo a mis padres contra la pared y los brazos levantados, nunca pensé verlos de ese modo, como tampoco imaginé ver la casa familiar avasallada de esa manera... 


\section{Rubén Isidoro Kotler}

La discusión sobre la cuestión de la repetición y la perdurabilidad del testimonio a lo largo del tiempo, como dije, no es nueva y sigue sin ser resuelta. Josefina Cuesta explica que el mantenimiento del relato a lo largo del tiempo es lo que le daría credibilidad y fiabilidad. La catedrática explica entonces que "además de la corroboración horizontal, sincrónica, de los otros testigos, el testimonio puede apoyarse en su propia corroboración a través del tiempo, en su permanencia en la diacronía". 45

En todo caso resulta conveniente, como ya mencioné, el entrecruzamiento de fuentes: contrastar todos los relatos y buscar la correlación entre lo que se dice y lo que suponemos realmente ocurrió. No me he quedado con aquello que se presenta repetitivo en ciertos relatos, sino en la búsqueda por encontrar los puntos de veracidad y credibilidad en los mismos, por indagar sus rupturas como así también las contradicciones internas que hacen al testimonio, por un lado, y a la apreciación personal y subjetiva que de los acontecimientos vividos tienen los sujetos sociales, percepción que no siempre es lineal aunque el investigador procure encontrar la coherencia interna del relato narrado.

En todos los relatos se produce una amalgama entre el pasado reciente con el presente que les toca vivir, es decir, que de los relatos se deduce por momentos una desilusión hacia el pasado vivido, donde algunos hitos son vivenciados como verdaderas derrotas políticas, y donde el presente abierto tiene la esperanza de ver al fin cumplidos algunos de los objetivos, después de casi 30 años de militancia. Si bien es cierto que hoy ya se han llevado a cabo varios juicios y algunos de ellos referidos a mega-causas, es probable que si yo volviera a entrevistar a Carlos o Felicidad, por ejemplo, parte de sus relatos podrían abandonar las desilusiones pasadas para mirar la perspectiva presente como un triunfo político que les permitió, en cierta forma, conseguir algo del principio de verdad y justicia históricamente exigidos.

\section{Consideraciones finales}

Para LaCapra, quien da el testimonio vuelve a vivir el horror al afirmar que "en la memoria traumática, el acontecimiento queda registrado e incluso se lo puede volver a vivir en el presente, a veces de manera compulsiva y repetitiva." 46 En el caso de las causas judiciales un equipo de psicólogos acompaña a los testigos en el camino de la testificación, lo que no sucede cuando el historiador avanza en una entrevista. LaCapra explica que es posible "que en ese proceso no intervenga una rememoración dirigida y consciente. Sin embargo, el acontecimiento vuelve en las pesadillas, en escenas que reaparecen vívidamente sin intervención de la voluntad, en ataques de angustia y en otras intrusiones repetitivas que son

45 Cuesta, Josefina. La Odisea de la Memoria. Historia de la memoria en España, S XX. Edit. Alianza. Madrid. 2009. P. 131.

${ }^{46}$ LaCapdra, Dominick (2001): Escribir la historia, escribir el trauma, Op. Cit. Pp.107 y 108. 


\section{Voces y memorias del trauma}

características de un andamiaje despótico". ${ }^{47}$ Y esto es verificable en el acto mismo del testimoniar.

En más de una entrevista, como las realizadas a Carlos y a Felicidad, tuve que interrumpir el cuestionario pues los testigos se angustiaban, lloraban y hasta se ahogaban. Sobre todo sucede cuando narraban la manera en cómo sus familiares habían sido secuestrados o la expectativa perdida de saber dónde está el cuerpo para la elaboración del duelo e incluso, cuando explicaban las expectativas de justicia que con el tiempo se habían ido desvaneciendo. Debe quedar claro que la función del historiador no es la función del psicoanalista y es lo que intenta establecer, en las diferencias, el historiador estadounidense cuando afirma que historiadores y psicoanalistas, suelen hablar un idioma distinto. ${ }^{48}$ La entrevista de historia oral, en este caso, nunca será liberadora ni podrá prometerle al testigo una salida del trauma pero, LaCapra insiste que "como aspecto de la elaboración del pasado, el recuerdo implica volver allá y estar aquí simultáneamente, y ser capaz de distinguir esos dos tiempos sin dicotomizarlos. En otras palabras, se recuerda lo que sucedió entonces sin perder la noción de que se vive y se actúa en el ahora, aun cuando en cierta medida quizá se vuelva a vivir todavía compulsivamente el pasado o a ser poseído por él." ${ }^{49}$ Estos son los principales desafíos a los que se enfrenta el historiador en el complejo proceso de reconstruir la trama de un pasado traumático y que vincula la tragedia personal con el drama colectivo. Si como afirmaban en la organización HIJOS a mediados de los 90, "todos somos hijos de una misma historia", la reconstrucción de ese pasado sigue siendo un deber compartido entre historiadores y familiares / militantes, para que la batalla por la memoria sea verdaderamente ganada. No se trata de revivir el trauma, pero sí de pensar en la dimensión ética de pensar una y otra vez un pasado que sigue siendo presente.

\section{Bibliografía}

AAVV (2003): Construcción de la Memoria. EUDEBA, Buenos Aires.

AAVV (2004): Usos de la Historia y políticas de la Memoria. Edit. Prensas Universitarias de Zaragoza, Zaragoza.

AAVV: Entre la palabra y el texto. Problemas en la interpretación de fuentes orales y escritas, Colección de Antropología y Literatura, Madrid.

CANDAU, Joël (2008): Memoria e Identidad, Ediciones del Sol, Buenos Aires.

CARNOVALE, Vera; LORENZ, Federico y PITTALUGA, Roberto comps. (2006): Historia, Memoria y Fuentes orales. Edits. Memoria Abierta y CEDINCI editores, Buenos Aires

CHARTIER, Roger (1992): El mundo como representación. Historia cultural: entre práctica y representación, Edit. Gedisa, Barcelona.

\footnotetext{
47 Ibídem.

48 Ibídem.

49 Ibídem.
} 


\section{Rubén Isidoro Kotler}

COLMEIRO, José (2005): Memoria histórica e identidad cultural. De la Postguerra a la Postmodernidad, Anthropos, Barcelona.

CUESTA BUSTILLO, Josefina (1985): "La Historia del tiempo Presente: estado de la cuestión”, en Estudia Histórica, Historia Contemporánea, Vol. 4, ediciones de la Universidad de Salamanca.

CUESTA BUSTILLO, Josefina (1996): “De la Memoria a la Historia”, en Entre el pasado y el presente. Historia y memoria, Universidad Nacional de Educación a distancia, Madrid.

CUESTA BUSTILLO, Josefina (2008): La odisea de la Memoria. Historia de la memoria en España. S. XXI, Alianza Editorial, Madrid.

CUESTA BUSTILLO, Josefina Comp. (1998): Memoria e Historia, Colección Ayer, Madrid.

DREIZIK, Pablo M. Comp. (2001): "La Memoria de las cenizas". Editado por la Dirección Nacional de Patrimonios, Museos y Artes. Buenos Aires.

FOLGUERA, Pilar: Cómo se Hace Historia Oral, Eudema.

GALASSO, Giuseppe (2001): Nada más que historia. Teoría y Metodología. Edit. Ariel, Barcelona.

HALBWACH, Maurice (2004): Los marcos sociales de la memoria. Edit. Anthropos, Barcelona.

HOBSBAWM, Eric (1998): Sobre la Historia, Edit. Crítica, Barcelona.

JELÍN, Elizabeth (2002): "Los trabajos de la Memoria, Edit. Siglo XXI, Madrid.

JELÍN, Elizabeth, DA SILVA CATELA, Luzmila comps. (2002): "Los archivos de la represión: documentos, memoria y verdad. Edit. S. XXI, Madrid.

LACAPRA, Dominick (2005): Escribir la historia, escribir el trauma, Nueva Visión, Buenos Aires.

LACAPRA, Dominick (2006): Historia en tránsito. Experiencia, identidad, teoría crítica, Fondo de Cultura económica, Buenos Aires.

LACAPRA, Dominick (2008): Historia y memoria después de Auschwitz, Prometeo - UNTREF, Buenos Aires.

LARA MESA, Ada Marina; MACÍAS G. Felipe y CAMARENA O. Mario coords. (2011): Los oficios del historiador. Taller y prácticas de la Historia Oral, Universidad de Guanajuato, México.

LLONA, Miren Coord. (2012): Entreverse. Teoría y metodología práctica de las fuentes orales, Argitalpen Zerbitzua Servicio Editorial, Gipuzkoa.

MORAES FERREIRA, Marieta y AMADO, Janaína Comps. (2010): Usos y abusos da história Oral, Fundación Getulio Vargas Editora, Río de Janeiro.

NECOECHEA, Gerardo y POZZI Pablo (2008): Cuéntame cómo fue. Introducción a la historia oral, Imago Mundi, Buenos Aires.

PASQUALI, Laura Comp (2008): Historia social e historia oral. Experiencias en la historia reciente de Argentina y América Latina, Homo Sapiens Ediciones, Rosario. PORTELLI, Alessandro (2004): La orden ya fue ejecutada. Roma, las Fosas Ardeatinas, la Memoria, Fondo de Cultura Económica, Buenos Aires.

RICOUER, Paul (2003): La memoria, la historia, el olvido, Edit. Trotta, Madrid. 


\section{Voces y memorias del trauma}

SAMUEL, Rapahel (2008): Teatros de la Memoria, V. I. Pasado y presente de la cultura contemporánea, Universitat de Valencia, Valencia.

SCHWARTZEIN, Dora Comp. (1991): "La Historia Oral". Colección, Los fundamentos de las Ciencias del Hombre. Centro Editor de América Latina. Buenos Aires.

THOMPSON, Paul (1988): Historia Oral, Edicions Alfons el Magnánim, Valencia. TODOROV Tzvetan (2000): "Los abusos de la memoria". Editorial Paidós Asterisco.

TODOROV Tzvetan (2002): Memoria del mal, tentación del bien. Indagación sobre el S XX, Edit. Península, Barcelona.

TRAVERSO, Enzo (2012): La historia como campo de batalla. Interpretar las violencias del S XX, Fondo de Cultura Económica, Buenos Aires.

VALLES, Miguel (1997): Técnicas Cualitativas de Investigación Social, Edit. Síntesis, Madrid.

WILLIAMS, Raymond (1997): Marxismo y Literatura, Ediciones Península, Barcelona.

YERUSHALMI, Yosef (1998): Usos del olvido, Edit. Nueva Visión, Buenos Aires. 